\title{
СФЕРА УСЛУГ И СОВРЕМЕННЫЕ ПРОБЛЕМЫ УПРАВЛЕНИЯ
}

\author{
(c) 2018 Рябова Елена Валентиновна \\ доктор экономических наук, профессор \\ Санкт-Петербургский университет технологий управления и экономики \\ 190103, г. Санкт-Петербург, Лермонтовский проспект, 44 \\ E-mail: thtk.05@mail.ru \\ (c) 2018 Носков Владимир Анатольевич \\ доктор экономических наук, профессор \\ Самарский государственный экономический университет \\ 443090, г. Самара, ул. Советской Армии, д. 141 \\ (c) 2018 Сосунова Лильяна Алексеевна \\ доктор экономических наук, профессор \\ Самарский государственный экономический университет \\ 443090, г. Самара, ул. Советской Армии, д. 141 \\ E-mail: kafedra-ks@yandex.ru
}

В статье проведено исследование универсальных подходов к управлению сферой услуг. Выделены три основных способа создания изменений в деятельности предприятий сферы услуг и показаны соответствующие современные управленческие решения.

Ключевые слова: управление, стратегические изменения, управление изменениями, сфера услуг.

Для более глубокого понимания сущности стратегических изменений и в сфере услуг рассмотрим подходы к управлению развитием этих процессов, которые встречающиеся в научной литературе. Все анализируемые подходы являются универсальными, т.е. их можно использовать вне зависимости от вида стратегических изменений и функциональной сферы их применения. Среди наиболее ранних подходов в проектировании стратегических изменений рассматривают стереотипно-шаблонный и контекстуально-сенситивный подходы [1]. Поэтапно изучим стереотипно-шаблонный подход, представленный двумя основными этапами.

Этап 1. Осуществляется постановка и решение вопроса по сущности стратегических изменений. Менеджеры диагностируют сложившуюся ситуацию, прогнозируют будущее состояние предприятия и проектируют рациональные изменения.

Этап 2. Подготавливается процесс организационных преобразований, для чего проводится поиск решений аналогичных задач в прошлом. Затем выбирается оптимальный тип стратегических изменений из ряда стереотипных шаблонов, при этом возможна частичная модификация его с учетом особенностей предприятия.

Указанный выше подход не требует форми- рования принципиально новых процессов изменений и обеспечения в определенной степени проработанности вопросов преобразований предприятия в связи с частым практическим применением шаблонных решений. Тем не менее, этот подход имеет ограничения в процессе использования необходимых шаблонов и в большинстве случаев не отражает всей картины сложившейся ситуации, а также стратегической направленности изменений.

При контекстуально-сенситивном подходе менеджер изучает все особенности контекста и специальных технологий, что позволяет найти нужное решение требуемой проблемы. Сущность подхода можно представить на основе четырехэтапной модели.

Этап 1. Аналогичен первому этапу в предыдущем подходе.

Этап 2. Анализируется контекст стратегических изменений в

сложившейся ситуации. Уникальность контекста организационных изменений в конкретном случае является причиной, из-за которой не выделяют глобальный универсальный метод осуществления стратегических изменений.

Этап 3. Оцениваются определенные контекстуальные характеристики по конкретной ситуации, которые могут быть неравноценными, в 
случае более высокой степени важности одних над другими.

Этап 4. Формируется оптимальный набор проектных факторов изменений. В результате осуществляется процесс изменений с максимальным учетом особенностей предприятия, не основанный на типовых решениях.

Обозначенные два подхода к управлению стратегическими изменениями определяют методы принятия решений, не отражают общей стратегической направленности изменений и взаимосвязи с макро- и микроокружением предприятия.

В современных научных экономических источниках часто можно встретить материал о двух различных подходах к управлению стратегическими изменениями, об активном и реактивном управлении [3].

Своевременное осознание существующих проблем неэффективного менеджмента и необходимости изменений может происходить благодаря анализу логики внутренних и внешних процессов предприятия. При таком варианте предприятие может заблаговременно выполнить все требуемые изменения. Тогда возможные внешние преобразования могут стать не угрозой благополучию, а возможностями для развития. Процесс управления изменениями становится активным, сами перемены менее затратными, обеспечивая при этом максимальный эффект. Подход к выявлению угроз в данной ситуации базируется на прогнозировании развития среды функционирования предприятия. Какие-либо изменения в деловой практике определяются кардинальными внешними преобразованиями, при этом прошлый опыт результативного управления теряет свою актуальность. В таких условиях важным становится понимание логики осуществляемых процессов и интуиция управляющих. Применение количественной информации и статистических методов также необходимо, но играет чаще уже вспомогательную роль.

Внешняя среда дает большой объем информации о происходящих явлениях в окружающем предприятие. Медленно данный поток информации усиливается и появляется новая проблема выявления общего потока тех сигналов, которые показывают возможные перемены. Слишком жесткая фильтрация получаемой информации опасна тем, что велика вероятность упустить в процессе отбора что-то важное. Так- же, обработать весь поток информации очень сложно, а постоянное реагирование на большое количество различных сигналов может привести к неэффективному использованию ресурсов. Найти «золотую середину» и увидеть важную информацию для предприятия является необходимым условием успешного управления изменениями [2].

Альтернативным вариантом исследования проблемы упущения результативности и необходимости изменений является реакция «постфактум», а именно в результате фактического снижения показателей в работе предприятия. Данное ухудшение характеризует, что неблагоприятные факторы внешней среды уже действуют или происходит существенная деградация рутинных процессов. В этом случае основным сдерживающим фактором для программы преобразований становится временной период, в рамках которого бизнес сможет поддерживать финансовую стабильность. Так, затраты на реализацию данной программы в сфере услуг с учетом убытков от текущей деятельности не должны приводить к критическому уменьшению стоимости активов, при котором работа предприятия становится невозможной. Такое управление изменениями рассматривают как реактивное.

При реактивном управлении стратегическими изменениями необходимо также понимать логику происходящего, как и при активном. Но такое понимание приходит не сразу. Как правило, вначале полученные низкие результаты деятельности списываются на временные трудности и особого беспокойства не вызывают. Когда ситуация развивается так, что опасения уже возникают, становятся достаточно серьезными, часто начинают использовать стандартные решения, не выходящие за пределы сформировавшихся систем управления и процессов. Только после того, как все успешные решения испробованы, но не получены ожидаемые результаты, приходит понимание о необходимости изменений в системе управления и деловых процессах. Большие временные затраты характеризуют сложность процесса планирования и внедрения разрабатываемых стратегий, структур и систем. Мероприятия, направленные на разработку и внедрение должны быть скоординированы между собой по времени и с изменениями во внешней среде предприятия. Для этого подготавливается план формирования целевого состояния, 
заложенного на этапе организационного проектирования.

Глубина понимания предприятием сферы услуг текущих и возможных изменений в конкурентной среде определяет рамки его поведения на рынке. Важным является и умение предвидеть данные преобразования, формировать и использовать их в своих интересах. Обозначим рычаги, которые сервисное предприятие может применить для повышения показателей своей деятельности. В настоящее время существует большой выбор вариантов стратегических изменений. Предприятия могут осуществлять диверсификацию своей деятельности в различных пределах. Можно выделить три основных способа создания изменений.

Изменение масштаба деятельности. Решения о масштабе помогают предприятию понять ограниченность доступных для него вариантов. Стратегические изменения, связанные с изменением масштаба, входят в число ключевых для сервисного предприятия и отражают ответы на четыре важных вопроса:

1. Какую услугу (или комплекс услуг) предприятие хочет предлагать на рынке и на какие потребительские нужды оно рассчитывает?

2. Какие географические регионы хочет охватить своими услугами?

3. Какие заинтересованные стороны (конкуренты, поставщики, СМИ, дистрибьюторы, конечные пользователи, суды, социально активные группы, правительственные органы) предприятие сферы услуг намерено вовлечь в определение услуг и рынка, в реализацию стратегических изменений?

4. Какие активы, технологии и характеристики может получить предприятие сферы услуг, чтобы работать на выбранных сегментах рынка?

Данные вопросы заставляют любое предпри- ятие сферы услуг четко определять, какие существуют возможности на рынке, каким бизнесом следует заниматься, какие топ-характеристики у него есть или оно может создать, чтобы реализовать свои возможности.

Изменение облика. Под обликом предприятия рассматривают то, как оно позиционирует себя по сравнению с нынешним или будущим положением с точки зрения восприятия услуги потребителями. В конечном счете, конкурентная мощь предприятия сферы услуг определяется выбранной им комбинацией различных элементов. При этом они могут быть связаны так, что формируют принципиальный, отличающийся облик для привлечения внимания клиентов.

Изменение целей. На выбор масштабов деятельности, узнаваемости облика предприятия сферы услуг влияют его рыночные цели. При этом необходимо получение ответов на следующие вопросы:

1. Каких результатов предприятие планирует достичь на рынке?

2. Что стремится получить для партнеров акционеров, контрагентов, сотрудников и общества в целом?

Стратегические изменения не могут обеспечить серьезных результатов на рынке и оптимальных экономических параметров, если не созданы преимущества для бизнеса, которые предприятие не реализует. Рассматривают данные преимущества только в рамках потребительского рынка. В связи с чем, сердцевиной любого стратегического изменения является создание новых возможностей для предприятия.

Описанные выше подходы, дающие общее представление о процессе реализации стратегических изменений, можно рассматривать как составную часть классического подхода к реализации стратегии предприятия сферы услуг.

\section{Библиографический список:}

1. Азоев Г.Л. Управление - фактор развития [Текст] / Г.Л. Азоев, А. Г. Поршнева. Москва. 2014.567 с.

2. Горшкова Л.А. Анализ организации управления. Аналитический инструментарий. Москва. 2013.208 с.

3. Драчева Е.Л. Дилемма стратегического менеджмента // Проблемы теории и практики управления. 2014. № 3. С. 98-103.

4. Рябова Е.В. Природа и причины возникновения стратегических изменений в экономических системах // Межвузовский сборник науч. ст. Экономика, финансы и управление в современных условиях. 2011 . № 7 (9).

5. Сосунова Л. А. Влияние сферы услуг на экономику /Л. А. Сосунова, Д.В. Чернова//Российское предпринимательство. 2003. № 3 (39). С. 33-37. -Режим доступа: http://www.creativeconomy.ru/articles/8676/.

6. Parasuraman A. Conceptual model of service quality and its implications for future research [Text]/A. Parasuraman, V. Zeithaml, L.A Berry // Journal of Marketing. 2015. Vol. 49. P. 41-50. 